\title{
¿Mejor no saber? Algunas consideraciones sobre la atribución de responsabilidad penal en caso de ignorancia
}

María Laura Manrique

CONICET - Argentina

\section{Introducción}

La discusión sobre la atribución de responsabilidad por casos de ignorancia deliberada ha cobrado relevancia teórica y práctica en los últimos años ${ }^{1}$. El excelente artículo de Ramon Ragués muestra, de forma clara y directa, cuáles son los problemas centrales, y el diferente tratamiento que esta figura recibe en los ámbitos del common law y del derecho continental ${ }^{2}$. En su trabajo, Ragués analiza la tensión entre, por un lado, la exigencia de conocimiento como un elemento básico para la atribución de responsabilidad penal a título de dolo y, por otro lado, la pretensión de resolver como dolososlos casos de

1 Por ejemplo, véase: Husak, Douglas y Callender Craig, 'WilfuI Ignorance, Knowledge, and the 'Equal Culpability' Thesis: A Study of the Deeper Significance of the Principle of Legality', Wis.L.Rev, 1994, 29, pp. 29-69; Luban, David, 'Contrived Ignorance', Georgetown Law Review, 87, pp. 957-980; Peels, Rick, 'Ignorance is Lack of True Believe: A Rejoinder to Le Morvan', Philosophia, 2011, 39, pp. 345-355.

2 Este artículo de Ramon Ragués puede considerarse el último (hasta ahora) de una saga sobre el tema que comienza con su trabajo doctoral (Ragués, Ramon, El dolo y su prueba en el proceso penal, Barcelona, Bosch, 1999) y, su libro sobre ignorancia deliberada (Ragués, Ramon, La ignorancia deliberada en Derecho penal, Barcelona, Atelier, 2007) aparte de otros artículos en diversas revistas especializadas sobre el mismo tema. 
ignorancia deliberada. Su opinión es que los casos de ignorancia deliberada muestran que dolo e imprudencia son insuficientes como las únicas formas de atribución de responsabilidad de los sistemas continentales ${ }^{3}$. Sin embargo, Ragués sostiene que cierto tipo de casos de ignorancia deliberada deben ser reprochados de la manera más grave, i.e. de modo similar al dolo. En esos casos, el agente muestra tal grado de indiferencia a las reglas penales y los bienes jurídicos que sería incomprensible un reproche leve o disminuido.

En general, coincido con Ragués en muchos de sus principales argumentos ${ }^{4}$. Por ejemplo, estoy de acuerdo en que las categorías de dolo y negligencia son insuficientes para dar cuenta de la variedad de elementos subjetivos que poseen relevancia práctica y también creo que esta variedad debe reflejarse específicamente en el tipo de sanción y el quantum de la pena. De igual manera estimo que la atribución de responsabilidad penal debería refinarse (sobre todo, en la tradición continental) para dar cuenta adecuadamente de los estados mentales de los agentes.

No obstante ello, hay ciertos temas y argumentos señalados por Ragués que merecen un mayor desarrollo a los efecto de ofrecer una adecuada solución al problema del reproche por ignorancia deliberada. En este trabajo destacaré, sin pretensión alguna de exhaustividad o sistematicidad, algunos de estos temas que considero más importantes. En especial, consideraré a continuación (i) la conexión entre ignorancia deliberada y dolo eventual, (ii) la estrategia de disminuir la noción de dolo a una estructura que no requiere conocimiento, (iii) la vinculación entre la noción de agente y la relevancia de los motivos, y (iv) el marco teórico necesario para darle cabida a los motivos.

3 Ragués, Ramon, 'Mejor no saber', Discusiones, No XIII, UNS, 2013, Discusiones, pp. 11-12

4 Sin embargo, estoy en desacuerdo sobre algunas de las ideas que expone sobre el tema en su libro La ignorancia deliberada en Derecho penal que no trataré aquí. Para ello véase: Manrique, María Laura, 'Ignorancia deliberada y responsabilidad penal', Isonomía, ITAM, México, en prensa. 
¿Mejor no saber? Algunas consideraciones sobre la atribución ...

\section{Mejor no saber. Sus presupuestos}

\section{II. a. Ignorancia y dolo eventual}

Ragués señala que, como una cuestión de hecho, muchos casos de ignorancia deliberada son resueltos mediante la figura del dolo eventual. Para este autor el hecho de que los códigos penales no definan al dolo y la imprudencia hace posible que los tribunales puedan resolver los problemas según 'la respuesta punitiva que consideran adecuada para cada caso o grupo de caso' ${ }^{5}$. Sin embargo, esta estrategia no es satisfactoria. En particular, subraya Ragués, cuando se resuelven a título de dolo eventual los casos de mera representaciónse generan dos problemas. En primer lugar, caen bajo el mismo título o etiqueta una gama variada de estados mentales a las que se atribuyen las mismas consecuencias normativas, y ello resulta en una pérdida de sensibilidad para la atribución de consecuencias. En segundo lugar, no se solucionan los casos de ignorancia deliberada en sentido estricto. Es decir, aquellos casos donde el agente intencionadamente evita adquirir los conocimientos mínimos ${ }^{6}$.

Estoy de acuerdo con Ragués acerca de los problemas que surgen a partir de la equiparación entre ignorancia deliberada y dolo eventual. Sin embargo, creo conveniente añadir a sus argumentos dos razones generales que también debería sumarse al debate. En primer lugar, dando por supuesto que la ignorancia deliberada es asimilable al dolo eventual, parece oportuno recordar que en la dogmática existe cierta discusión sobre si el dolo eventual merece ser reprochado del mismo modo que los otros tipos de dolo ${ }^{7}$. En otras palabras, aun cuando se asumiese que el dolo eventual es la clave para entender a la ignorancia

5 Ragués, Ramon, 'Mejor no saber', op.cit., p 18.

6 Ragués, Ramon, 'Mejor no saber', op.cit., p 18.

7 Por ejemplo, Bustos Ramírez sostiene que el dolo eventual merece un reproche menor que otras formas de dolo Bustos Ramírez, 'Política Criminal y Dolo Eventual', Revista Jurídica de Catalunya, 1984, pp. 29-48. Al respecto, véase también Manrique, María Laura, Acción, dolo eventual y doble efecto, Marcial Pons, Barcelona, 2012. 
deliberada, todavía es necesario analizar si ambos merecen o no un reproche disminuido.

En segundo lugar, hay buenas razones para rechazar la equiparación entre ignorancia deliberada y dolo eventual ya que estas figuras se refieren a etapas o momentos diferentes de la acción humana. Por una parte, en los casos de dolo eventual el sujeto sabe exactamente aquello que hace -de hecho, él quiere hacer lo que está haciendopero conoce que es probable que su acción genere determinadas consecuencias dañinas que no desea. El agente actúa sin ningún error de comprensión y la probabilidad de que una consecuencia dañina efectivamente se produzca depende de cómo es el mundo y sus relaciones causales. Por otra parte, en los casos de ignorancia deliberada el agente no sabe si está realizando determinada conducta porque carece de información relevante para comprender aquello que está haciendo. Aunque su ignorancia sea deliberada sigue siendo un caso de desconocimiento. Un ejemplo puede ayudar a aclarar la idea. María, que por ciertos motivos quiere mantener oculto el hecho de que acaba de dar a luz, pone a su hijo recién nacido en un armario y lo tapa con toallas para que sus padres -que imprevistamente llegan a visitarlano escuchen el llanto de su hijo. Ella sabe que como consecuencia de ello es probable que el niño muera. Finalmente, el niño fallece. Para la dogmática este es un caso claro de dolo eventual ${ }^{8}$. María sabe lo que está haciendo y quiere poner a su hijo en un armario, pero no quería que este muriera. Supongamos ahora que María pone a su hijo en un bolso y se lo da a su amiga Ana para que ella lo guarde en un armario. Ante la pregunta de su amiga, María responde que es mejor que no lo sepa. La amiga sospecha que algo no va bien, pero accede a 'guardar el bolso'. Si eliminamos la consecuencia desagradable, ¿qué datos poseemos para correlacionar esa conducta con una acción diferente a la de guardar un bolso? Sin duda, podrían darse una inmensa cantidad de descripciones posibles, pero - una vez que se elimina la consecuencia- estamos incapacitados para atribuir una acción de

8 Esta es una reformulación de un ejemplo tomado de Díaz Pita, María del Mar, El dolo eventual, Valencia, Tirant lo Blanch, 1994, p. 42. 
manera clara. La descripción de la acción de 'guardar un bolso' es compatible con otras tales como la de esconder un animal, de guardar dinero, esconder droga, ocultar un objeto robado, o, simplemente, la de guardar un bolso. En nuestro ejemplo, Ana desconoce exactamente aquello que está haciendo. Por supuesto, ello también la lleva a desconocer las consecuencias de lo que hace. A su vez, si suprimimos la consecuencia dañina puede que incluso en el caso del dolo eventual entendamos que María puso en riesgo a su hijo. Pero, si suprimimos las consecuencias en el accionar de Ana no tenemos ningún rasgo que se pueda utilizar para atribuir responsabilidad.

\section{II. b. Ignorancia deliberada y ausencia de conocimiento}

A diferencia del apartado anterior en los que cierta representación del agente sugería la posibilidad de asimilar la ignorancia deliberada al dolo eventual, en este apartado analizaré qué tipo de responsabilidad puede atribuirse a quien no posee ningún tipo de conocimiento concreto sobre la situación delictiva. La mayoría de autores considera que en esa situación no se puede considerar al comportamiento como doloso. Sin embargo, para Ragués, el problema es que, en algunas de estas ocasiones, el reproche a título de imprudencia o la impunidad parecen extraños e insatisfactorios ${ }^{9}$.

En la dogmática continental, Jakobs ha sido uno de los primeros autores que ha puesto en duda la idea de que el dolo requiere conocimiento ${ }^{10}$. Para Jakobs, el diferente tratamiento que el código penal alemán da a las situaciones de error de tipoy error de prohibición son un contrasentido. Para Jakobs, las normas del código penal alemán

9 Por esa razón, han surgido algunas estrategias para castigar dichas situaciones. Algunas sentencias del Tribunal Supremo español son un ejemplo de esta estrategia. Ellos se apropian de la figura norteamericana del willful blindness para poder reprochar en esas situaciones. Ragués, Ramon, 'Mejor no saber', op.cit. p. 19 y ss.

10 Jakobs ha mantenido estas ideas en numerosos lugares. Véase, por ejemplo, Jakobs, Günther, Derecho Penal-Parte General, Madrid, Marcial Pons, 1995, p. 314; Jakobs, Günther, Dogmática del Derecho penal y la configuración normativa de la sociedad, Civitas, Madrid, 2004, p. 189. 
obligan a responder de forma injustificadamente benigna ante ciertos supuestos de desconocimiento, concretamente los que denomina casos de 'imprudencia dirigida a un fin' o 'ceguera ante los hechos ${ }^{11}$. Estas consecuencias son injustas porque favorecen a quien desconoce cierto tipo de cosas (los hechos) y perjudican a otras (quienes desconocen la existencia de ciertas normas). A su vez, esto puede tener el efecto de premiar a quien desconoce por indiferente y castigar a quien conoce por concienzudo y precavido ${ }^{12}$.

Una solución a este desafío es atenuar la relación entre de dolo y conocimiento. Para ello, la estrategia sería vincular al dolo a la noción de indiferencia ${ }^{13}$. Ragués ${ }^{14}$ señala que, en relación al derecho penal,u-

${ }^{11}$ Ragués, Ramon, 'Mejor no saber', op.cit., p. 26.

12 Jakobs, Estudios de Derecho Penal, Madrid, Civitas, 1997, p. 378. También en página 138; Ragués, Ramon, 'Mejor no saber', op.cit., pp. 12-13. La tesis de que no hay razones para tratar el error de tipo y el error de prohibición de diferente manera no es extraña, al menos en el ámbito de la filosofía moral. Así autores como Anscombe o Zimmerman sostienen, con diferente terminología y esquemas conceptuales, esta misma idea. Véase, Anscombe, G.E.M, 'Two kinds of error', The Journal of Philosophy, Vol. 60, Nº14, 1963, Symposium: Human Action pp. 393-401; Zimmerman, Michael 'Moral Responsibility and Ignorance' Ethics, 107, 1997, pp. 410-426. Una reconstrucción de este otro ámbito de discusión serviría para advertir que aun cuando se concediese que ambos errores deben ser equiparados, no se seguiría que ellos tengan que ser resueltos del modo menos benigno para el agente. Todavía se podría sostener que en ambos casos debe exonerarse al agente. Por ejemplo, véase Zimmerman, Michael, 'Moral Responsibility and Ignorance', op.cit., p. 425.

${ }^{13}$ Quien en un primer momento estableció la diferencia entre dolo eventual e imprudencia basado en la indiferencia fue Engisch, Untersuchungen über Vorsatzund und Fahrlässigkeit im Strafrecht, Berlín, 1930, pp. 186 y ss. (Cita extraída de Puppe, Ingeborg, La distinción entre dolo e imprudencia, Hammurabi, Buenos Aires, 2010, p. 83)

14 Ragués, Ramon, La ignorancia deliberada en derecho penal, op.cit. En ocasiones utilizaré el libro de Ragués para completar sus ideas, aunque fue publicado varios años antes que el trabajo que se está comentando aquí sirve para clarificar algunas dudas y problemas que no pueden identificarse fácilmente por la limitación de espacio que posee un artículo en comparación al libro. Aunque en este artículo hay tesis que no se sostienen expresamente los presupuestos 
¿Mejor no saber? Algunas consideraciones sobre la atribución ...

na persona puede ser considerada en una doble faceta: primero como potencial infractor y, segundo, como individuo que reclama protección. Así, el mensaje de la pena también es doble. Por un lado se dirige a quienes reclaman protección ya que la pena contribuye a la pacificación social restaurando la vigencia de los valores que son puestos en duda por el agente al cometer el delito. Por otro lado, trasmite el mensaje a quien infringe la norma de que utilizar medios ilícitos para conseguir sus objetivos está condenado al fracaso ${ }^{15}$.

De manera correlativa, las razones que justifican la diferencia de reproche entre dolo e imprudencia también son dos. Primero, para que la sanción pueda reafirmar los valores amenazados y contribuir a la pacificación del grupo social es necesario que se responda más severamente frente a la hostilidad que ante la mera indiferencia. Segundo, si la pena se dirige a frustrar al infractor, entonces es necesario aplicar consecuencias más graves sobre la persona que ha conseguido su objetivo ilícito. De todo ello se seguiría que quien actúa con dolo directo debe ser castigado de mayor manera que quien simplemente dañó un interés protegido como consecuencia de su comportamiento, i.e. dolo eventual o imprudencia ${ }^{16}$. A su vez, los actos que reflejan indiferencia deben ser castigados de manera más leve que los actos que reflejan hostilidad ${ }^{17}$.

De esta manera, la indiferencia no solo juega un papel determinante para comprender en qué se distingue el dolo de la imprudencia sino que también es esgrimido como una justificación del mayor reproche en casos de delitos dolosos. Por ello, no debe sorprender que Ragués, por ejemplo, admita que los casos de indiferencia grave tienen que ser castigados también de forma grave, i.e., los casos que caen bajo el rótulo de dolo eventual son castigados como casos de hostilidad ${ }^{18}$.

de su trabajo siguen siendo los mismos. Por esa razón asumo que las tesis que defiende expresamente o podría defender también son similares a la del libro.

15 Ragués, Ramon, La ignorancia deliberada en Derecho penal, op.cit., p. 182.

16 Un problema de esta fundamentación es que no explica por qué motivo castigamos en general los casos de tentativa, donde el sujeto no consiguió su objetivo ilícito, de modo más grave que los casos de su equivalente consumado imprudente.

17 Ragués, Ramon, La ignorancia deliberada en Derecho penal, op.cit., pp. 180-182.

18 Ragués, Ramon, La ignorancia deliberada en Derecho penal, op.cit., p.182. 
María Laura Manrique

La importancia que posee la indiferencia se aprecia claramente cuando Ragués afirma:

Desde un punto de vista expresivo, tanto en los casos de mero conocimiento como de desconocimiento se advierte una indiferencia hacia el valor lesionado: en el primer supuesto porque el sujeto no desiste de sus planes pese a ser consciente de que estos entrañan un riesgo de lesión; y en el segundo porque el interés lesionado importa tan poco al sujeto que este ni tan siquiera se da cuenta de que lo pone en peligro. Con todo, entre ambas situaciones existe una distinción que radica en el hecho de que mientras en el caso del conocimiento la indiferencia tiene como referente concreto el objeto de protección, en el caso de desconocimiento tal indiferencia se manifiesta, de manera más difusa, respecto de todos aquellos intereses susceptibles de ser lesionados. Esta sutil diferencia puede explicar que se traten de manera distinta el dolo eventual y la imprudencia ${ }^{19}$.

En síntesis, el reproche será más grave en caso de conocimiento porque el agente es indiferente ante una situación concreta que puede lesionar bienes jurídicos específicos. En cambio, en los casos de ignorancia el agente es indiferente ante una variedad de posibles lesiones a bienes jurídicos.

Creo que hay un germen de verdad en la propuesta de Ragués, pero ella posee dos dificultades. En primer lugar, si tanto en situaciones de conocimiento como en las de desconocimiento el agente puede ser indiferente, la indiferencia sigue siendo un rasgo que no puede ser utilizado para separar los casos más graves de los menos graves. En este sentido, la indiferencia también es ineficiente para distinguir los casos de dolo de aquellas otras situaciones de negligencia. Por ello, la estrategia de Ragués de identificar 'clases' de indiferencia según si el agente conoce o desconoce una determinada situación riesgosa no le permite solucionar los casos de ignorancia deliberada del modo en queél pretende. Así, en casos de ignorancia deliberada en sentido es- 
¿Mejor no saber? Algunas consideraciones sobre la atribución ...

tricto el sujeto desconoce y por lo tanto la 'indiferencia se manifiesta, de manera más difusa, respecto de todos aquellos intereses susceptibles de ser lesionados' y las razones del reproche siguen siendo las mismas que para el delito imprudente.

En segundo lugar, creo que entender la justificación del mayor reproche de los delitos dolosos sobre los imprudentes haciendo énfasis en la noción de indiferencia genera una brecha entre, por un lado, la noción de agente y explicación de la acción humana y, por otro, la atribución de responsabilidad. No puedo justificar directamente esta idea en los límites de este trabajo y, por ello, solo sugeriré sus principales lineamientos a la luz de la distinción entre responsabilidad básica y responsabilidad consecuencial ${ }^{20}$.

El término 'responsabilidad', al igual que sucede con nociones como causa, razonamiento, acción, posee más de un significado ${ }^{21}$. En general, en el ámbito jurídico utilizamos el término 'responsable' o 'no responsable' para afirmar que alguien es apto, o no, para sufrir determinadas consecuencias desagradables (responsabilidad consecuencial). Así, si Juan es responsable de matar a Pedro él puede ser castigado. Sin embargo, hay otra acepción que es central pero que con cierta frecuencia es pasada por alto: la llamada responsabilidad en sentido básico.

Una persona es básicamente responsable cuando posee la habilidad de explicar y dar razones por lo que hizo como agente. Es la capacidad de ofrecer justificaciones y excusas por aquellas acciones que uno realizó. Esta habilidad es innata y nos atraviesa como agentes racionales ya que, como agentes racionales, no podemos dejar de lado la aspiración de explicar nuestra conducta en términos de razones ${ }^{22}$.

${ }^{20}$ Sigo en este punto a la conocida reconstrucción de Gardner. Al respecto, véase, Gardner, John, Ofensas y defensas -Ensayos selectos sobre filosofia del derecho penal-, Marcial Pons, Barcelona, 2012, pp. 197-219. Véase también Dworkin, Ronald, Sovereign Virtue: the Theory and Practice of Equality, Harvard University Press, 2000, p. 287.

${ }^{21}$ Platts, Mark, Ser responsable -Exploraciones filosóficas-, Instituto de Investigaciones Filosóficas (UNAM), México, 2012, pp. 21 y ss.

${ }^{22}$ Por supuesto, ello no quiere decir que una explicación de nuestra conducta en 
No solamente debo ofrecer razones sino que, en un contexto explicativo, ellas deben ser las razones por las que se ha actuado, i.e. las que determinaron la conducta ${ }^{23}$.

Dado que esta es una aspiración que posee todo ser racional, y ella está en el centro de la idea de responsabilidad, un diseño institucional será más o menos adecuado según facilite o dificulte que los agentes ejerzan su responsabilidad en sentido básico. Y, en gran medida para que esté justificado atribuir responsabilidad consecuencial, i.e., imputar consecuencias desagradables a una persona, es necesario que primero ella haya sido considerada básicamente responsable. Así, estructurar la atribución de responsabilidad en términos de indiferencia no da lugar a que el agente explique adecuadamente las razones por las que actuó.

Si un agente actúa con ira, por miedo, por codicia, para salvar a alguien, etc., en general es consciente de que su actuar tiene determinadas características, e.g., es dañino, incorrecto, peligroso, heroico, etc. Cuando afirmamos que una persona actúa de manera ignorante, indiferente, desconsiderada, etc., queremos decir que nosotros como observadores vemos algo que esa persona no vio al momento de actuar, que ella no posee información completa sobre aquello que está haciendo, i.e. ella no es consciente de todo el panorama. En este sentido, las razones por las que el agente puede esgrimir al momento de actuar son parciales según el punto de vista del observador. Todas las razones que pueda dar el agente serán insuficientes porque el observador está analizando un evento que el agente conceptualmente no pudo ver. Así, si las razones que el agente da son siempre insuficientes (porque se refieren a otro evento), ello sugiere que esas razones son irrelevantes. En síntesis, lo esencial en este modo de atribuir responsabilidad es aquello que el

términos de razones siempre es suficiente para justificar un comportamiento. Hay malas y buenas razones. Gardner, John, Ofensas y defensas, 'El sello de la responsabilidad', op.cit., pp. 197-202.

${ }^{23}$ En general, el derecho penal limita las razones por las cuales uno puede obtener con éxito una justificación o una excusa. Sin embargo, este no es el tema aquí. Lo que quiero resaltar es el valor de tener la posibilidad de esgrimir razones y explicar por qué realizamos determinada conducta. Para un desarrollo de estas ideas, véase: Gardner, John, Ofensas y defensas, 'Justificaciones y razones', op.cit., pp. 125-135. 
observador imputa (atribuye), desplazando el papel central del agente en la explicación de sus acciones. Este sistema está estructurado para que las razones del agente sean insuficientes e ineficientes. En consecuencia, este es un sistema que disminuye el valor que posee tratar a las personas como agentes racionales. Si esto es así, no tener en cuenta aquello que el agente creyó y quiso al momento de hacer lo que hizo, que imputa dolo ante comportamientos indiferentes e ignorantes es un diseño que descuida la responsabilidad en sentido básico y se aleja de la idea de agente como eje central del proceso.

Una consecuencia, conectada con esto, es que la fundamentación del reproche en base a las diferentes clases de indiferencia deja al margen o disminuye la importancia de los estados mentales. Calificar a alguien como indiferente es señalar (atribuir) que su comportamiento carecía de determinadas características, por ejemplo, cierto cuidado, consideración, etc. Por el contrario, considerar los estados mentales como relevantes es descubrir o averiguar qué quería realizar el agente, qué conocimientos poseía para utilizar los medios para conseguir su objetivo y qué razones o motivos tenía el agente al momento de realizar la conducta. Aquí no importa aquello que el agente debía tener en consideración (cuidado) sino qué motivos efectivamente impulsaron su acción. Dado que Ragués pretende darle relevancia a los motivos para fundamentar que los casos de ignorancia deliberada en sentido estricto puedan ser castigados de manera más grave que la imprudencia, creo que ello lo compromete con encontrar otro tipo de fundamentación para justificar el mayor reproche de los delitos dolosos sobre los imprudentes.

\section{Mejor no saber. La propuesta}

Para Ragués los casos de ignorancia deliberada se sitúan en un lugar híbrido entre dolo y negligencia. En particular, ello ocurre cuando el agente sospecha de que se está introduciendo en un ámbito ilícito y, sin embargo, no investiga al respecto. Siguiendo a Luban $^{24}$, Ragués destaca la relevancia de los motivos por los que un

${ }^{24}$ Luban, David, 'Contrived Ignorance', op.cit., pp. 957-980. 
individuo decide permanecer en situación de ignorancia. Para ello, distingue entre aquellos agentes que no investiga por debilidad moral (caracterizados como 'agentes tipo avestruz' por el mito de que esas aves esconden la cabeza ante los problemas) y aquellos otros que no quiere salir de su ignorancia solo para eludir la responsabilidad (identificados como 'agentes tipo zorro' por el estereotipo de animal calculador y astuto). Un ejemplo de este último tipo de casos sería el de un individuo que no abre una maleta, aún cuando sospecha que su contenido es una sustancia ilícita, para beneficiarse de su ignorancia en caso de ser apresado. Para Ragués, estos casos pueden ser castigados incluso más gravemente que si fueran realizados con conocimiento. Así, para Ragués hay dos razones que justifican tratar este tipo de desconocimiento de forma más grave que la mera imprudencia y similar al dolo:

En primer lugar, porque desde un punto de vista expresivo no solo cabe valorar el desconocimiento, sino los motivos que han llevado a él: no en vano, un observador medio nunca diría que quien ha querido mantenerse en la ignorancia se encuentra en una situación de error, máxime si partía de la sospecha inicial de que su comportamiento podía lesionar algún interés -ciertamente no concretado- colectivo o de otro sujeto. Y, en segundo término, porque si semejantes casos quedan en la impunidad, la pena estará dejando de cumplir su función de provocar el fracaso del delincuente en situaciones en las que, sin embargo, este habrá alcanzado su propósito criminal. Con la impunidad en tales casos se dirigiría a la ciudadanía el mensaje de que en determinadas circunstancias peligrosas para terceros resulta más aconsejable inhibirse que preocuparse. $^{25}$

A continuación, y durante lo que resta del trabajo, dedicaré las dos secciones siguientes a analizar brevemente ambos argumentos. 
¿Mejor no saber? Algunas consideraciones sobre la atribución ...

\section{III. a. Ignorancia deliberada y motivos}

Al igual que Ragués, creo que los motivos son relevantes para la atribución de responsabilidad. La plausibilidad de este enfoque queda de manifiesto en situaciones en las que el agente cuenta con una legítima razón para la ignorancia. Por ejemplo, supongamos que a un individuo $X$ le exigen transportar una maleta y lo amenazan con dañar seriamente a su familia en caso de que la abriese. ¿No sería plausible sostener que $X$ no debe ser castigado? En este caso, $X$ desconoce el contenido de la maleta y sus sospechas acerca del eventual contenido ilícito que transporta son insuficientes para atribuirle responsabilidad ya que la amenaza grave y probable que enfrenta constituye una defensa (excusa, justificación, etc.) jurídicamente admisible. En otras palabras, sus motivos -el propósito de evitar un grave daño a su familia- ofrecen razones legítimas para evitar la responsabilidad. A su vez, si los motivos son determinantes para excluir la responsabilidad, no habría que descartar que, en algunas situaciones, ellos sean también relevantes para disminuir el reproche.

Creo que esta relevancia de los motivos implica un desafío para las concepciones epistémicas del dolo (i.e, dolo = conocimiento), que Ragués ha suscripto en otros trabajos. Por ejemplo, una década atrás, el sostenía que:

...hoy en día, el dolo se concibe (de forma explícita o implícita) solo como conciencia de la realización de un comportamiento típico objetivo. Por expresarlo de forma simple pero contundente, el dolo ya no es conocimiento y voluntad, sino únicamente conocimiento $^{26}$.

Sin embargo, esta exclusividad de los elementos epistémicos en la configuración del dolo es difícil de reconciliar con atribuir relevancia a los motivos del agente. No estoy afirmando que Ragués haya pasado por alto este problema. Por el contrario, es parte central de su trabajo,

${ }^{26}$ Ragués, Ramon, 'Consideraciones sobre la prueba del dolo', REJ-Revista de Estudios de la Justicia - No 4 - Año 2004, p. 13. 
aunque no estoy segura de que su solución sea satisfactoria. A continuación expondré algunas dudas sobre su propuesta.

Al momento de modelar el concepto de dolo, Ragués defiende una concepción normativa del dolo ${ }^{27} \mathrm{y}$, en particular, insiste en una reconstrucción de esa figura depurada de elementos volitivos ${ }^{28}$. En este marco es conveniente reflexionar acerca de por qué razón, dentro de su teoría, podría fundamentarse la necesidad de dar cabida a los motivos. A diferencia de lo que ocurre con el dolo, no tiene sentido insistir en que los motivos deben ser entendidos en sentido normativo. Los motivos son relevantes por el modo en que ellos determinan la acción humana y, en ese sentido, ellos ayudan a explicar nuestra conducta. Por tanto, en un contexto explicativo, la descripción de los motivos de la conducta de un agente no solo se refiere a las razones que el agente tenía para hacer lo que hizo sino que también tienen que ser las razones por la cual el agente hizo lo que hizo, i.e. deben ser tanto una razón guía como una explicativa ${ }^{29}$.

Por ello, creo que enfrentamos a la siguiente disyuntiva: (a) le damos cabida a los motivos para resolver, a título de dolo, los casos de ignorancia deliberada, o (b) se mantiene que la estabilización de expectativas normativas es, en última instancia, el fundamento de los reproches más graves. En el primer caso, es necesario abandonar una noción del dolo que no incluya a los elementos volitivos (e.g., un conocimiento entendido en sentido normativo) y la fundamentación del mayor reproche del delito doloso como una cuestión de estabilización de expectativas normativas cumple un papel secundario o accesorio.

En el segundo caso, se debe abandonar la idea de que los motivos pueden ser útiles para distinguir y reprochar de forma similar al dolo

27 Ragués, Ramón, El dolo y su prueba en el proceso penal, op.cit., p. 249.

${ }^{28}$ Creo que es un error entender que el dolo se conforma solo con elementos epistémicos y no con elementos epistémicos y volitivos como tradicionalmente se lo consideraba, sin embargo esto no es relevante para el punto que pretendo señalar aquí. Para una defensa de ello véase, Manrique, María Laura, Acción, dolo eventual y doble efecto, op.cit., pp. 107-136.

${ }^{29}$ Gardner, John, Ofensas y defensas, op.cit., pp. 113 y ss.; en el mismo sentido Peralta, José M., Motivos reprochables, Marcial Pons, Barcelona, 2012, p. 199. 
los casos de ignorancia deliberada en sentido estricto. Esta última opción aunque es conceptualmente posible me parece desafortunada. Dejando de lado la cuestión acerca de si existe o no una disposición jurídica específica que imponga o excluya la necesidad de tener en cuenta los motivos para la ignorancia deliberada, ¿qué justificación podría invocarse para descartar a esos motivos? Sin dudas, la persecución penal sería más simple si el Estado no tuviese que probar un estado mental específico para obtener una condena en virtud de la ignorancia deliberada. Sin embargo, ello sería similar a sostener que el Estado, en virtud de exigencias de simplicidad probatoria, no tiene necesidad de probar la voluntad de ejecutar (o el conocimiento de la probable realización) del resultado típico. Por supuesto, que el Estado debe probar que la ignorancia fue deliberada y, por esa razón, podría generarse la ilusión de que la persecución penal no se desentiende de la prueba de los estados mentales. Pero, parece incoherente que estos estados sean relevantes para calificar la ignorancia y, al mismo tiempo, negarle relevancia para determinar el grado de responsabilidad.

\section{III. b. Ignorancia deliberada y los códigos penales}

Según Ragués, la ausencia de una regulación específica de la ignorancia deliberada impide graduar adecuadamente las penas conforme a los distintos tipos de imputación subjetiva, e.g., con intención, conocimiento, desconocimiento provocado, etc ${ }^{30}$. Por esa razón, concluye que los sistemas penales continentales deberían acoger una mayor cantidad de tipos de reproche.

Entre estas situaciones particulares que merecen un tratamiento específico que no puede consistir en una reconducción automática a los casos de intención, conocimiento o desconocimiento se cuentan, sin duda, los supuestos de ignorancia deliberada en sentido estricto que se han descrito en las anteriores páginas. Estos casos son, como se anunciaba, una pequeña brecha que pone en evidencia algunos de los graves 
María Laura Manrique

problemas que presenta el vigente sistema continental de imputación subjetiva ${ }^{31}$.

Como he señalado anteriormente, estoy de acuerdo con Ragués en la necesidad de una reforma legal que imponga mayor sensibilidad en el tratamiento de diversos estados mentales de los agentes. Sin embargo, Ragués también sugiere queaun cuando nuestros sistemas no sean modificados, se podrían reprochar como dolosas las conductas con ignorancia deliberada. En su opinión, es conveniente aceptar esta alternativa antes de dejar que ellas resulten impunes (o con un reproche sensiblemente menor).

Creo que esta solución es inaceptable y a continuación daré algunos argumentos en contra de ella. Para Ragués, los sistemas jurídicoscomo el español o argentino -que no consagran una definición expresa de 'dolo'- permiten reprochar de la manera más grave a los casos paradigmáticos de ignorancia deliberada. Es decir, para él no existirían 'problemas insalvables de legalidad'32. En gran medida, su argumento se basa en el ámbito de libertad interpretativa que resulta del hecho de que no existen definiciones legales expresas que limiten el sentido de 'dolo', 'imprudencia', etc., y, por tanto, impongan una solución específica a los problemas de qué cuenta como dolo o imprudencia ${ }^{33}$.

Por razones de simplicidad, denominaré 'tesis de la asimetría' al argumento de Ragués. Esta tesis señala que frente a definiciones legales expresas los jueces no poseen libertad para apartarse de esos significados, pero que en caso de que no existan esas definiciones, los jueces pueden desarrollar discrecionalmente propuestas interpretativas. En este último caso, la dogmática cumpliría un papel fundamental, suministrando argumentos específicos que limiten la arbitrariedad interpretativa.

Sin dudas, la dogmática posee amplia libertad para desarrollar sus propuestas en el ámbito del conocimiento científico. Ello implica que

${ }^{31}$ Ragués, Ramon, 'Mejor no saber', op.cit., p.34.

32 Ragués, Ramon, 'Mejor no saber', op.cit., p. 33.

${ }^{33}$ Ragués, Ramon, 'Mejor no saber', op.cit., p.33. 
los dogmáticos no enfrentan restricciones institucionales para sus propuestas interpretativas. Por el contrario, los jueces no gozan de la misma libertad; en virtud de los compromisos derivados del imperio de la ley en el Estado de Derecho, ellos están vinculados por las decisiones del legislador ya que ellos tienen la obligación de justificar sus decisiones en esas normas existentes. Esta vinculación de los jueces y demás agentes que aplican el derecho exige fidelidad al modo o manera en que el legislador utilizó el lenguaje ('las palabras de la ley'). Estas ideas acerca de los diferentes papeles institucionales de la dogmática y los jueces son bien conocidas, pero tal vez por su misma familiaridad, en ocasiones es fácil pasar por alto ciertos presupuestos y consecuencias: ${ }^{34}$

1. Las normas son expresadas por los textos promulgados por la autoridad. Dado que los textos son motivacionalmente inertes, es conveniente asumir que las normas son el significado de los textos legales.

2. El significado de los textos legales depende del modo en que el legislador haya usado las palabras de la ley.

3. El legislador puede usar las palabras de la ley de dos maneras diferentes (e incompatibles). O bien, usa esas palabras en su sentido ordinario, o bien, se aparta del uso ordinario.

4. En general, el legislador usa las palabras que emplea en la formulación de sus normas porque ellas tienen ya un determinado significado en la comunidad. Pero, en caso de apartarse del uso ordinario del lenguaje, el legislador tiene que indicar cuál es el sentido específico de sus palabras. En ese caso, es usual que el legislador imponga mediante definiciones legales (i.e, definiciones estipulativas como las del término 'violencia' en el art. 77 del CP Argentino, que incluye al uso de medios hipnóticos y narcóticos) el significado específico que le ha atribuido a sus palabras.

5. El hecho de que el legislador introduzca una definición no es todavía una prueba concluyente de que haya usado de ese modo el

${ }^{34}$ Para un desarrollo minucioso de estas ideas véase: Alchourrón C. y Bulygin, E.,'Definiciones y normas', Análisis lógico y Derecho, Centro de Estudios Constitucionales, Madrid, 1991, pp. 439-463. 
término en cuestión. Aunque es relativamente infrecuente que el legislador introduzca una definición y luego no la use, nada impide que existan estas discrepancias -sobre todo en textos que sufren diversas enmiendas a lo largo del tiempo. Por ello, el dato decisivo es el modo en que el legislador usa efectivamente la palabras y no tanto lo que dice en sus definiciones acerca de cómo va a usar esas expresiones- ${ }^{35}$.

6. Cualquier ampliación o restricción de los significados atribuidos por el legislador a sus textos es una modificación del mandato del legislador. Ello se produce tanto cuando los intérpretes (i) atribuyen un sentido técnico a palabras de la ley que el legislador ha usado convencionalmente, (ii) atribuyen un sentido convencional a palabras de la ley para las que el legislador ha estipulado un sentido técnico específico y (iii) atribuyen un sentido técnico ' $\mathrm{X}$ ' a palabras de la ley que a las que el legislador les ha asignado otro sentido técnico ' $Z$ '.

De allí se siguen una consecuencia directa en contra de la tesis de la asimetría. La vinculación del juez al legislador tiene contenido similar tanto en casos donde hay una definición legal de las palabras de la ley como en los casos donde esas definiciones no existen. Por una parte, en los casos relativamente infrecuentes en que el legislador ha definido expresamente un cierto término,pero lo ha usado de otro modo, esas definiciones legales no imponen restricciones a los jueces. Por otra parte, aun cuando no existan definiciones expresas los jueces están comprometidos a usar las palabras de la ley en el mismo sentido en que las ha usado el legislador. En resumen, a efectos de fundar sus decisiones en la ley, los jueces tienen que determinar en qué sentido el legislador efectivamente utilizó el término 'dolo', 'imprudencia', etc.

\footnotetext{
${ }^{35}$ Por ejemplo, un indicio de que el legislador no ha usado su definición de 'violencia' sería el hecho de que hubiese establecido diferentes sanciones para los delitos cometidos con violencia y aquellos realizados mediante el uso de medios hipnóticos o narcóticos. Véase, Alchourrón C. y Bulygin, E., 'Definiciones y normas', op.cit., pp. 440-454.
} 
¿Mejor no saber? Algunas consideraciones sobre la atribución ...

¿De qué manera se puede analizar el modo en que se usa un concepto como el de dolo en caso de que no exista una definición explícita? Aun cuando no haya una respuesta concluyente a este interrogante, es posible señalar una manera paradigmática en la dogmática penal contemporánea. Por ejemplo, para los autores que defienden la vinculación entre dolo y conocimiento, un indicio de que el legislador ha asumido esa conexión se encuentra en las razones que excluyen el dolo. Así, por ejemplo, en otro trabajo Ragués señala:

... para afirmar que se ha obrado dolosamente basta con acreditar que el sujeto activo ha actuado representándose la concurrencia en su conducta de los elementos objetivos exigidos por el tipo...Una conclusión que, por lo demás, resulta plenamente coherente con la circunstancia de que aquello que excluya el dolo en los textos legales vigentes sea solo el error y no una inexistente causa de eliminación de la voluntad ${ }^{36}$.

No creo que estas sean razones para afirmar que el dolo es solo conocimiento pero sí es una razón para entender que el conocimiento forma parte del dolo. Incluso si el legislador no ha definido expresamente el dolo, en códigos como el español o el argentino, existe de hecho la figura del error. Una consecuencia de lo que dijo el legislador es que si el agente posee una creencia equivocada o, incluso, no posee una creencia $\mathrm{x}$ en relación a cierto comportamiento no se puede atribuir responsabilidad a título de dolo. Por esa razón, incluso aunque haya razones morales para reprochar de la forma más grave en casos de ignorancia deliberada, los códigos penales que poseen la figura del error (aunque no hayan definido el dolo) establecen un límite para el reproche de esas conductas.

Finalmente, una dogmática penal que asume el valor del principio de legalidad debería insistir en la necesidad de una reforma legisla-

36 Ragués, Ramon, 'Consideraciones sobre la prueba del dolo', op.cit., pp. 15-16. En el mismo sentido, con un argumento desarrollado véase: Gimbernat Ordeig, Enrique, 'Acerca del dolo eventual', en Estudios de Derecho Penal, Tecnos, Madrid, 1990, pp. 240-265. 
tiva para castigar a la ignorancia deliberada con la misma severidad que al dolo. Por supuesto, si la conducta de un agente que obra con ignorancia deliberada queda sin reproche la pena no cumple una de sus funciones específicas: provocar el fracaso del plan del delincuente. No es necesario negar aquí las limitaciones o ineficiencias de nuestras prácticas del castigo para dar cuenta de aquellos casos impunes de ignorancia deliberada. Sin embargo, es necesario resaltar que esta limitación está basada en una razón de principio: no está justificado castigar penalmente más que en aquellos casos expresamente determinados -y de la manera taxativamente establecida- en nuestros ordenamientos jurídicos penales.

\section{Balance}

El trabajo de Ramon Ragués es interesante, claro y novedoso. Como señalé al comienzo, muchos de sus argumentos y tesis, e.g., la insuficiencia de las categorías de dolo e imprudencia, son especialmente apropiados. Sin embargo, en este artículo he destacado algunos problemas y desafíos que aún están pendientes. En especial, he señalado que:

- La ignorancia deliberada en ningún caso puede asimilarse a la estructura del dolo eventual.

- Utilizar la noción de indiferencia para justificar el reproche del modo más grave en los casos de ignorancia deliberada es ineficiente e injustificado. Es ineficiente porque tanto en los casos de dolo como imprudencia el sujeto puede actuar de manera indiferente. Está injustificado porque utilizar la noción de indiferencia para justificar el mayor reproche genera una brecha entre la noción de agente, la explicación de la acción y la atribución de responsabilidad.

- Para que Ragués pueda dar cabida a la noción de motivos para distinguir los casos de ignorancia deliberada en sentido estricto podría ser necesario justificar el reproche de manera distinta al modo en que lo realiza el autor.

Particularmente, y aunque no intentaré fundamentarlo aquí, creo que una teoría que considere como base de la atribución de respon- 
sabilidad al conocimiento y la voluntad está en mejor condiciones de explicar por qué razón nos parece más grave los delitos cometidos por quien desconoce deliberadamente (i.e., queriendo desconocer) que quien no alcanzó ese grado de conocimiento por ser descuidado o negligente al respecto. Independientemente de otras razones conceptuales, al tener en cuenta más rasgos característicos de la acción, la ausencia o la presencia de ciertos elementos pueden hacer variar de una gama más amplia las maneras el reproche (hay más casos que se pueden analizar). A su vez, esta base facilita la incorporación de los motivos como criterio para diferenciar la ignorancia más grave de la menos grave.

Por último, creo que la dogmática el único camino que tiene para generar atribuciones de responsabilidad conceptualmente más sensibles es reclamar que los códigos penales reflejen esa variedad de situaciones.

\section{Bibliografía}

Alchourrón C. y Bulygin, E., 'Definiciones y normas', Análisis lógico y Derecho, Centro de Estudios Constitucionales, Madrid, 1991, pp. 439-463.

Anscombe, G.E.M, 'Two kinds of error', The Journal of Philosophy, Vol. 60, Nº14, 1963, Symposium: Human Action pp. 393-401

Bustos Ramírez, 'Política Criminal y Dolo Eventual', Revista Jurídica de Catalunya, 1984, pp. 29-48.

Díaz Pita, María del Mar, El dolo eventual, Valencia, Tirant lo Blanch, 1994.

Dworkin, Ronald, Sovereign Virtue: the Theory and Practice of Equality, Harvard University Press, 2000.

Gardner, John, Ofensas y defensas -Ensayos selectos sobre filosofia del derecho penal-, Marcial Pons, Barcelona, 2012.

Jakobs, Günther, Derecho Penal -Parte General, Madrid, Marcial Pons, 1995.

Jakobs, Estudios de derecho penal, Estudios de Derecho Penal, Madrid, Civitas, 1997. 
María Laura Manrique

Jakobs, Günther, Dogmática del Derecho penal y la configuración normativa de la sociedad, Civitas, Madrid, 2004

Gimbernat Ordeig, Enrique, Estudios de Derecho Penal, Tecnos, Madrid, 1990.

Husak, Douglas y Callender Craig, 'WilfuI Ignorance, Knowledge, and the 'Equal Culpability' Thesis: A Study of the Deeper Significance of the Principle of Legality', Wis.L.Rev, 1994, 29, pp. 29-69

Luban, David, 'Contrived Ignorance', Georgetown Law Review, 87, 1999, pp. 957-980.

Manrique, María Laura, Acción, dolo eventual y doble efecto, Marcial Pons, Barcelona, 2012.

Manrique, María Laura, 'Ignorancia deliberada y responsabilidad penal', Isonomía, ITAM, México, (en prensa).

Peels, Rick, 'Ignorance is Lack of True Believe: A Rejoinder to Le Morvan', Philosophia, 2011, 39, pp. 345-355

Peralta, José M., Motivos reprochables, Marcial Pons, Barcelona, 2012.

Platts, Mark, Ser responsable -Exploraciones filosóficas-, Instituto de Investigaciones Filosóficas (UNAM), México, 2012

Puppe, Ingeborg, La distinción entre dolo e imprudencia, Hammurabi, Buenos Aires, 2010,

Ragués, Ramon, El dolo y su prueba en el proceso penal, Barcelona, Bosch, 1999

Ragués, Ramon, 'Consideraciones sobre la prueba del dolo', REJ Revista de Estudios de la Justicia - No 4 - Año 2004, pp. 13-26.

Ragués, Ramon, La ignorancia deliberada en Derecho penal, Barcelona, Atelier, 2007

Ragués, Ramon, 'Mejor no saber', Discusiones, N XIII, UNS, 2013, Zimmerman, Michael, 'Moral Responsibility and Ignorance' Ethics, 107, 1997, pp. 410-426. 